\title{
Effects of larval exposure to sublethal doses of Bacillus thuringiensis var. israelensis on body size, oviposition and survival of adult Anopheles coluzzii mosquitoes
}

Steven Gowelo ${ }^{1,2^{*}}$, James Chirombo ${ }^{3}$, Jeroen Spitzen ${ }^{1}$, Constantianus J. M. Koenraadt ${ }^{1}$, Themba Mzilahowa ${ }^{4}$, Henk van den Berg' ${ }^{1}$, Willem Takken ${ }^{1}$ and Robert McCann ${ }^{1,2,5}$

\begin{abstract}
Background: Application of the larvicide Bacillus thuringiensis var. israelensis (Bti) is a viable complementary strategy for malaria control. Efficacy of Bti is dose-dependent. There is a knowledge gap on the effects of larval exposure to sublethal Bti doses on emerging adult mosquitoes. The present study examined the effect of larval exposure to sublethal doses of Bti on the survival, body size and oviposition rate in adult Anopheles coluzzii.

Methods: Third-instar An. coluzzii larvae were exposed to control and sublethal Bti concentrations at $\mathrm{LC}_{20}, \mathrm{LC}_{50}$ and $\mathrm{LC}_{70}$ for $48 \mathrm{~h}$. Surviving larvae were reared to adults under standard colony conditions. Thirty randomly selected females from each treatment were placed in separate cages and allowed to blood feed. Twenty-five gravid females from the blood-feeding cages were randomly selected and transferred into new cages where they were provided with oviposition cups. Numbers of eggs laid in each cage and mortality of all adult mosquitoes were recorded daily. Wing lengths were measured of 570 mosquitoes as a proxy for body size.

Results: Exposure to $L C_{70} B$ ti doses for $48 \mathrm{~h}$ as third-instar larvae reduced longevity of adult An. coluzzii mosquitoes. Time to death was 2.58 times shorter in females exposed to $L C_{70} B t i$ when compared to the control females. Estimated mortality hazard rates were also higher in females exposed to the $L C_{50}$ and $L C_{20}$ treatments, but these differences were not statistically significant. The females exposed to $L C_{70}$ concentrations had $12 \%$ longer wings than the control group $(P<0.01)$. No differences in oviposition rate of the gravid females were observed between the treatments.

Conclusions: Exposure of An. coluzzii larvae to sublethal Bti doses reduces longevity of resultant adults and is associated with larger adult size and unclear effect on oviposition. These findings suggest that anopheline larval exposure to sublethal Bti doses, though not recommended, could reduce vectorial capacity for malaria vector populations by increasing mortality of resultant adults.
\end{abstract}

Keywords: Bacillus thuringiensis var. israelensis, Sublethal dose, Larval source management, Mosquito, Vector control

*Correspondence: gowellsteve@gmail.com

${ }^{1}$ Laboratory of Entomology, Wageningen University \& Research, Wageningen, The Netherlands

Full list of author information is available at the end of the article



(c) The Author(s) 2020. This article is licensed under a Creative Commons Attribution 4.0 International License, which permits use, sharing, adaptation, distribution and reproduction in any medium or format, as long as you give appropriate credit to the original author(s) and the source, provide a link to the Creative Commons licence, and indicate if changes were made. The images or other third party material in this article are included in the article's Creative Commons licence, unless indicated otherwise in a credit line to the material. If material is not included in the article's Creative Commons licence and your intended use is not permitted by statutory regulation or exceeds the permitted use, you will need to obtain permission directly from the copyright holder. To view a copy of this licence, visit http://creativecommons.org/licenses/by/4.0/. The Creative Commons Public Domain Dedication waiver (http://creativecommons.org/publicdomain/zero/1.0/) applies to the data made available in this article, unless otherwise stated in a credit line to the data. 


\section{Background}

Malaria remains a major public health problem in the world, especially in Africa where the incidence rate has remained stable, and in some cases even increased, over the past few years [1] despite widespread use of control methods [2]. Widespread insecticide resistance has been reported in the important malaria vectors across all classes of insecticides used on insecticide-treated bednets and indoor residual spraying [3-6]. Further, outdoor feeding and resting by malaria vectors, whether in response to use of insecticide-treated bednets [7-10] or as a natural behaviour in some vector populations, expose people to residual malaria transmission. This has led to global advocacy for additional vector control tools to eliminate residual malaria transmission by targeting outdoor resting and feeding, as well as insecticideresistant vectors [9]. Larval source management (LSM) indiscriminately kills malaria vectors before they emerge as adult mosquitoes [11] and relies on separate modes of action from those used in insecticide-treated bednets and indoor residual spraying. Thus, LSM can contribute to malaria control where the vectors exhibit exophagic and exophilic behaviours, and in settings where insecticide resistance has emerged.

Strains of the bacteria Bacillus thuringiensis var. Israelensis (Bti) are widely used as active ingredients in larvicides because they do not cause harm to non-target organisms or the environment $[12,13]$. The bacteria produce parasporal crystalline protein inclusions (Cry and Cyt) which are lethal only to specific insect taxa [14]. In mosquitoes, the protein crystals bind to specific receptors exposed on the surface of the plasma membrane and then insert into the membrane, creating lytic pores in microvilli of apical membranes [15] that disturb the cell's osmotic balance, resulting in cell lysis and consequently death of the larvae $[16,17]$. The low persistence of Bti toxins under field conditions [18] makes Bti an ecofriendly larvicide even when used in repeated treatments from three to seven years [19]. This rapid degradation, however, necessitates repeated applications of the larvicide for effective control of target organisms.

Environmental conditions experienced by mosquitoes during larval growth and development affect adult fitness in a number of ways [20-22]. Nutritional and larvicidal stresses can reduce adult size, survival and fecundity in different mosquito species [23-26]. One such larvicidal stressor could be sublethal doses of Bti. Sublethal Bti concentrations reduce adult mosquito survival rates, lower blood-engorgement rate and egg production, increase development time from egg to adult, and decrease offspring sex ratio in Aedes aegypti [27]. Similarly, sublethal doses of Bti may cause adverse effects on life parameters of exposed Ae. aegypti and their unexposed first-generation progeny [26]. Prolonged development time, reduced longevity and reduced reproductive rates were observed in Anopheles superpictus exposed to sublethal doses of $B t i$ [28].

Mosquito larvae may be exposed to sublethal concentrations of Bti under field conditions. This could result from some or all of these factors: (i) anthropological factors such as poor measurement of $B t i$ in relation to habitat size and poor calibration of instruments used in weighing the product; (ii) biotic factors such as growth of vegetation in habitats that may trap the product and reduce larva-product contact; and (iii) abiotic factors such as water $\mathrm{pH}$, turbidity and temperature, which may degrade the product or modulate product activity within the mosquito. These doses may result directly or indirectly in biological changes in the surviving larvae and consequently impact adult fitness. Though not ideal, sublethal Bti doses could impact vector populations and malaria parasite transmission, and should thus be well understood. The purpose of this study was to understand how these doses affect the survival, body size and oviposition rate of Anopheles coluzzii, an important human malaria vector in Africa.

\section{Methods \\ Anopheles coluzzii colony}

The mosquitoes used in all experiments came from an An. coluzzii colony maintained at the insectary of the Laboratory of Entomology of Wageningen University, The Netherlands. Standard colony rearing conditions for the immature stages consisted of plastic larval trays (10 $\times 25 \times 8 \mathrm{~cm}$ ) filled with salt-treated demineralised water $(0.008 \mathrm{~g} / \mathrm{ml})$ to reduce the potential for larval pathogen infections. In each start-up tray, salt-treated water containing approximately 200 first-instar larvae was pipetted. Larvae were provided $0.1 \mathrm{mg} / \mathrm{larva}$ Tetramin fish food (Tetrawerke, Melle, Germany) for the first instars and $0.3 \mathrm{mg} /$ larva for the other larval stages. All pupae were removed from the trays and placed in salt-treated demineralised water in $100 \mathrm{ml}$ plastic cups in $30 \times 30 \times$ $30 \mathrm{~cm}$ cages. Emerging adults were fed $6 \%$ sugar solution ad libitum. From day 3-4 post-emergence, adult females were offered human blood for 2-3 h per day for 11 days. A membrane feeding system (Discovery Workshops, Acrington, Lancs, UK) [29] was used for the blood-feeding.

\section{Sublethal Bti concentration determination}

The protocol of Becker and Rettich [30] was adopted for preparing a $B t i$ solution. Fifty milligrams of a water-dispersible granule (WDG) formulation of $B t i$ (VectoBac ${ }^{\circledR}$ WDG, Valent BioSciences) were added to $10 \mathrm{ml}$ distilled water. The mixture was homogenised at $700 \mathrm{rpm}$ for 10 
min and vortexed for $15 \mathrm{~min}$. Then $1 \mathrm{ml}$ of the homogenised suspension was added to $49 \mathrm{ml}$ distilled water to make a stock solution of $100 \mathrm{mg} / \mathrm{l}$. The suspension was vortexed for $5 \mathrm{~s}$ at maximum speed. Aliquots of the suspension ranging from 0 to $1200 \mu \mathrm{l}$ were pipetted into plastic cups containing $100 \mathrm{ml}$ salt-treated demineralised water to produce final experimental concentrations ranging from 0 to $0.4 \mathrm{mg} / \mathrm{l}$ (Additional file 1: Table S1).

Over six different days, larvae were exposed to three treatment cups per concentration and three control cups (salt-treated demineralised water). Twenty-five thirdinstar larvae were placed in each cup, and mortality was recorded after 24 and $48 \mathrm{~h}$. If pupation occurred, the pupae were removed, and their numbers were excluded from calculations. Based on the proportion of larval mortality observed at each $B t i$ concentration after $48 \mathrm{~h}$, concentrations producing about $20 \%$ mortality $\left(\mathrm{LC}_{20}\right), 50 \%$ mortality $\left(\mathrm{LC}_{50}\right)$ and $70 \%$ mortality $\left(\mathrm{LC}_{70}\right)$ were fixed and used throughout the subsequent experiments.

\section{Tests of sublethal doses on fitness parameters}

To determine the effects of sublethal exposure to Bti during larval development, trays with third-instar larvae were obtained from the insectary and were exposed to experimental conditions for $48 \mathrm{~h}$. These experiments were replicated six times. For each replicate, we used three control trays containing the salt-treated demineralised water and three trays for each of the three sublethal $B t i$ concentrations $\left(\mathrm{LC}_{20}, \mathrm{LC}_{50}\right.$ and $\left.\mathrm{LC}_{70}\right)$. During the 48 - $\mathrm{h}$ exposure period, each tray was provided $20 \mathrm{mg}$ fish food per day. Air temperature in the climate chamber was maintained at $27 \pm 1{ }^{\circ} \mathrm{C}$. All dead and moribund larvae were counted after 24 and $48 \mathrm{~h}$. After the 48 -h exposure period for each replicate, all surviving larvae from the same treatment were pooled and placed in new trays with fresh salt-treated water only (i.e. no Bti). Sixty milligrams of fish food were given to the larvae in each tray daily. All emerging pupae were placed in plastic cups $(100 \times 50 \mathrm{~mm}$ diameter $)$, which were placed in $30 \times 30$ $\times 30 \mathrm{~cm}$ cages, separated by treatment and replicate. The emerging adults were fed $6 \%$ sugar solution ad libitum. On days 5 and 6 post-emergence, 30 females from each treatment were indiscriminately removed using a mouth aspirator and placed in new cages, still separated by treatment and replicate. The females in each cage were given a chance to feed on human blood via arm feeding for $10 \mathrm{~min}$ per day for two days. The same person was used for all the blood-feeding. The mosquitoes were also provided with $6 \%$ sugar solution in the new cages when not blood-feeding. At $24 \mathrm{~h}$ after blood-feeding, oviposition cups were introduced in the cages and 25 randomly selected gravid females were kept in the cage. The other five females were taken back to the non-oviposition cages which contained mosquitoes which were not given blood meals. All dead mosquitoes from day of emergence in both oviposition and non-oviposition cages were counted daily until 37 days post-emergence. The records were separated by treatment, replicate and sex. The number of eggs laid was counted daily for seven days and separated by treatment and replicate. Wing lengths were measured of 570 mosquitoes as the distance between the alula and the wing tip, excluding fringe scales, using CMEX DC 5000 binocular microscope (Euromex, The Netherlands) and Image Focus Version 3 software. The wing measurements were separated by treatment, replicate and sex of the mosquitoes.

\section{Data analysis}

To determine the impact of Bti concentration on wing length, we fitted a linear mixed model to account for the effect of treatment (as a fixed effect) and replicate (as a random effect). We fitted a random intercept model where the effect of replicate was allowed to deviate from the overall, to investigate if replicate as a covariate contributed to the overall variation in the wing length. Kaplan Meier curves were plotted to visualize mosquito survival patterns over time. To estimate the hazard rate of mortality for each level of Bti concentration, we fitted a multivariate Cox proportional hazards model with treatment and replicate as covariates. A Poisson generalized linear model with treatment and wing length as covariates was fitted to investigate their effect on mean number of eggs laid by gravid females. The level of significance was set at 0.05 . All statistical analyses were carried out in $\mathrm{R}$ version 3.6.1.

\section{Results}

Determination of sublethal concentrations of Bti on An. coluzzii larvae

Mortality of An. coluzzii larvae exposed as third instars to Bti for $48 \mathrm{~h}$ increased with increasing Bti concentrations (Fig. 1). Based on these larval mortality rates, we selected $0.03 \mathrm{mg} / \mathrm{l}, 0.12 \mathrm{mg} / \mathrm{l}$ and $0.28 \mathrm{mg} / \mathrm{l}$ as Bti concentrations for $\mathrm{LC}_{20}, \mathrm{LC}_{50}$ and $\mathrm{LC}_{70}$ respectively (Additional file 1: Table S1).

\section{Effect of larval exposure to sublethal Bti on post-larval stage counts in An. coluzzii}

A total of 2902 adult mosquitoes emerged from larvae from the control and treatment trays. The number of mosquitoes surviving to the adult stage decreased with increasing Bti concentrations (Table 1). In the control groups, there were 679 (69.9\%) females and 293 (30.1\%) males. For the treatment groups, $524(60.8 \%)$ and 337 (39.1\%), $423(66.7 \%)$ and 211 (33.3\%), and $315(72.4 \%)$ and $120(27.6 \%)$ were females and males for $\mathrm{LC}_{20}, \mathrm{LC}_{0}$ 


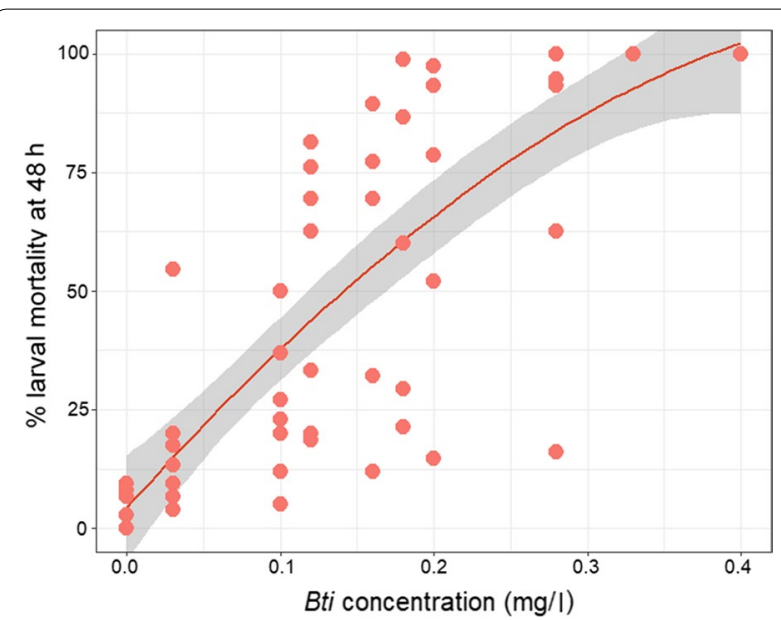

Fig. 1 The relationship between Bti concentration and mortality of Anopheles coluzzii larvae after $48 \mathrm{~h}$. Each point represents the Bti concentration and corresponding larval mortality in each cup per replicate. Overlapping points indicate the same values for multiple cups. The red line is the weighted mean larval mortality due to the varied Bti concentrations and the grey area represents the 95\% confidence interval. See Additional file 1:Table S1 for the number of replicates run for each Bti concentration

and $\mathrm{LC}_{70}$, respectively. Treatment did not have an effect on the sex ratio of mosquitoes surviving to the adult stage $\left(x^{2}=0, d f=3, P=1\right)$.

\section{Effect of larval exposure to sublethal Bti concentrations on wing length}

Five hundred and seventy wings were measured and separated by sex: 402 and 168 for female and male mosquitoes, respectively. For both sexes, increasing Bti concentration was associated with an increase in wing length (Table 1), but the difference was only significant between the control and $\mathrm{LC}_{70}$. The mean wing length of the adult female $A n$. coluzzii exposed to $\mathrm{LC}_{70} B t i$ concentrations increased by $12 \%$ compared to the control group (Additional file 1: Table S2). Similarly, adult An. coluzzii males exposed to $\mathrm{LC}_{70}$ concentrations had wings that were $20 \%$ longer than the control group (Additional file 1: Table S3).
Survival of adult An. coluzzii after exposure to sublethal Bti concentrations as larvae

Survival of adult An. coluzzii decreased with increasing Bti concentration exposure as larvae (Fig. 2). The highest cumulative survival probabilities for both female and male mosquitoes were observed in the control and $\mathrm{LC}_{20}$ concentrations. The survival probabilities dropped more rapidly in males compared to females.

An increasing trend of hazard ratios (HR) with increasing Bti concentrations was observed in adult females compared with the control group (Table 2). When exposed to $B t i \mathrm{LC}_{70}$ as larvae, the proportional hazard rate for mortality as adult females was about three times higher than the rate from the control group $(\mathrm{HR}=$ 2.58, CI: $1.44-4.53, P<0.01)$. The mortality hazard ratio for adult males was also significantly increased when exposed to Bti LC70 as larvae, (HR $=1.54, \mathrm{CI}$ : $0.99-2.38$, $P=0.049$; Table 2).

\section{Effect of sublethal Bti concentrations on number of eggs laid by adult $A$. coluzzii}

There was an apparent trend of decreasing number of eggs laid per cage of 25 females with increasing concentration of Bti exposure as larvae (Fig. 3). However, these differences were not statistically significant (Table 3 ). Further, the mean wing length of gravid females per cage did not have an effect on the number of eggs laid (Table 3).

\section{Discussion}

This study assessed potential effects of larval exposure to sublethal doses of Bti on fitness parameters of adult $A n$. coluzzii. We observed that larval exposure to sublethal $B t i$ doses reduced survival of adult An. coluzzii mosquitoes. For both male and female An. coluzzii, the lowest survival probability was recorded at the highest Bti concentration. It is not well understood how the larvicide reduces longevity of the adults that survive exposure as larvae. However, there is evidence that a Bti toxin, Cry1C, has a toxic effect to brain cells of larvae of a lepidopteran, Lymantria dispar, in vitro [31]. This suggests that Bti may cause similar damage to the adult mosquitoes surviving

Table 1 Effect of larval exposure to sublethal Bti on post-larval stages in An. coluzzii

\begin{tabular}{lllll}
\hline Treatment & Mean no. of pupae \pm SE & Mean no. of adults \pm SE & $\begin{array}{l}\text { Mean wing length (mm) of adult } \\
\text { males } \pm \text { SE }(n)\end{array}$ & $\begin{array}{l}\text { Mean wing length (mm) } \\
\text { of adult females } \pm \text { SE }(n)\end{array}$ \\
\hline Control & $162.0 \pm 9.02$ & $159 \pm 7.33$ & $2.39 \pm 0.02(57)$ & $2.36 \pm 0.02(160)$ \\
$\mathrm{LC}_{20}$ & $143.5 \pm 13.68$ & $137 \pm 9.04$ & $2.36 \pm 0.03(40)$ & $2.41 \pm 0.02(133)$ \\
$\mathrm{LC}_{50}$ & $105.7 \pm 13.63$ & $93 \pm 10.23$ & $2.42 \pm 0.04(37)$ & $2.50 \pm 0.02(63)$ \\
$\mathrm{LC}_{70}$ & $72.5 \pm 7.98$ & $64 \pm 5.32$ & $2.48 \pm 0.02^{*}(34)$ & $2.58 \pm 0.05^{*}(46)$ \\
\hline
\end{tabular}

*Indicates statistical significance of the treatment in relation to the control $(p<0.01)$. See Additional file 1: Tables $\mathrm{S} 2$ and $\mathrm{S} 3$ for the effect sizes of larval exposure to the sublethal Bti concentrations on wing lengths of adult males and females, respectively 

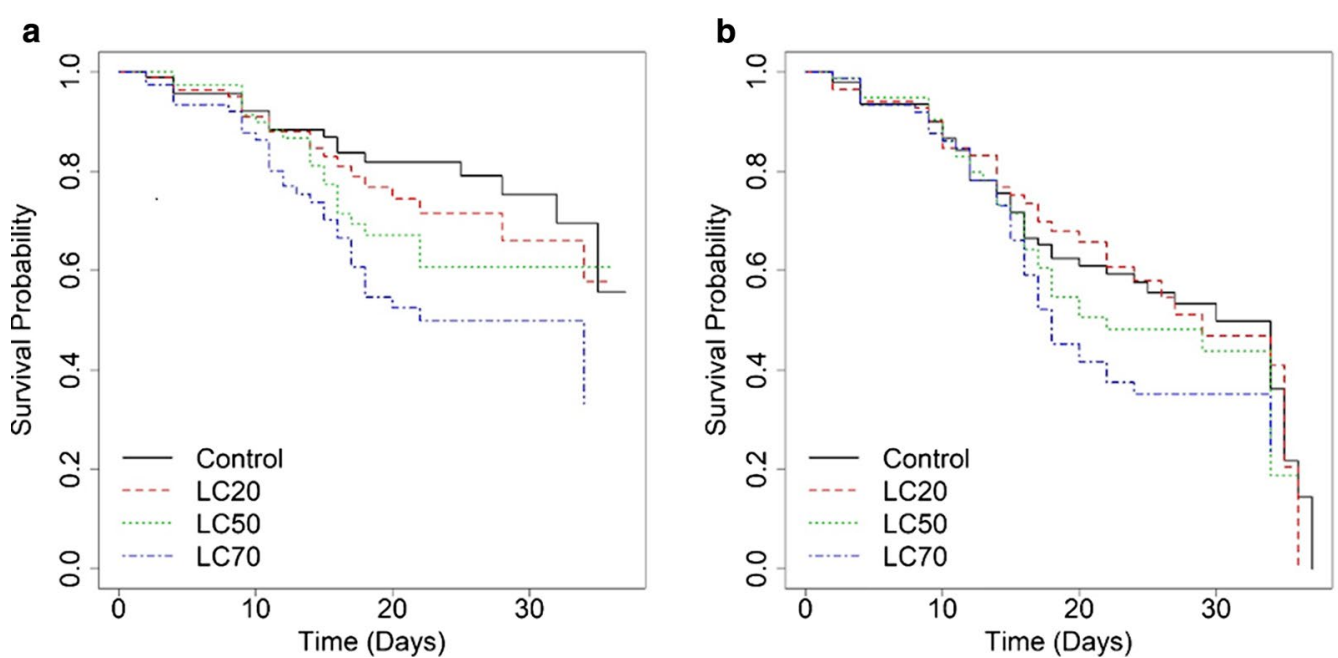

Fig. 2 Survival curves for Anopheles coluzzii adults exposed to different concentrations of Bti as larvae. a Survival curves for adult female An. coluzzii. b Survival curves for adult male An. coluzzii

Table 2 Mortality of adult An. coluzzii exposed to sublethal Bti concentrastions as larvae

\begin{tabular}{|c|c|c|c|c|c|c|}
\hline \multirow[t]{2}{*}{ Variable } & \multicolumn{3}{|c|}{ Time to death (females) } & \multicolumn{3}{|c|}{ Time to death (males) } \\
\hline & $H R$ & $95 \% \mathrm{Cl}$ & $P$-value & $H R$ & $95 \% \mathrm{Cl}$ & $P$-value \\
\hline $\mathrm{LC}_{20}$ & 1.25 & $0.65-2.38$ & 0.5 & 0.95 & $0.6-1.51$ & 0.83 \\
\hline $\mathrm{LC}_{50}$ & 1.62 & $0.86-3.05$ & 0.14 & 1.25 & $0.8-1.96$ & 0.33 \\
\hline $\mathrm{LC}_{70}$ & 2.58 & $1.44-4.63$ & 0.001 & 1.54 & $0.99-2.38$ & 0.049 \\
\hline
\end{tabular}

Note: Bold values indicate statistical significance of the treatment in relation to the control $(p<0.05)$

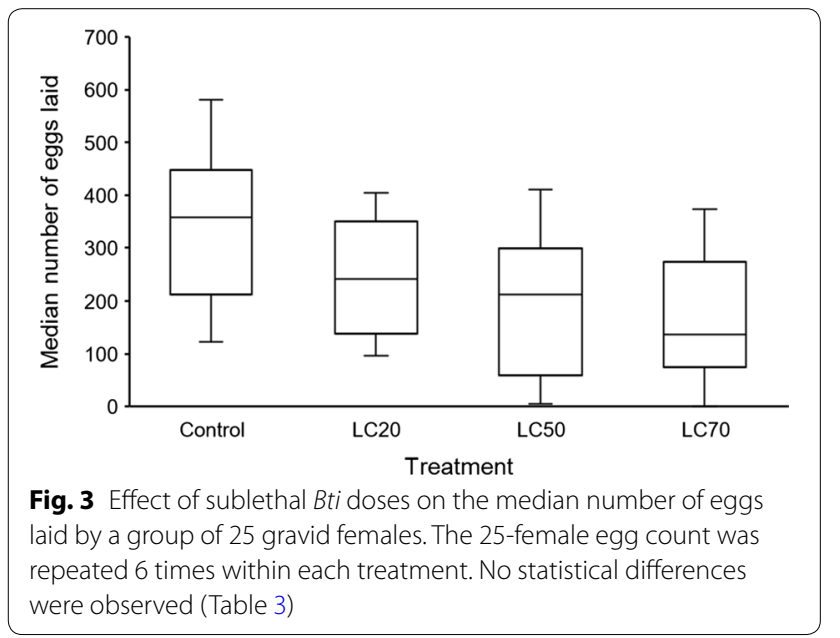

larval exposure to sublethal doses which may reduce their life spans. Similar results have been reported for Culex quinquefasciatus exposed to sublethal doses of cypermethrin as both larvae and adults [32]. The authors
Table 3 Effect of sublethal Bti and wing length on egg-laying in female An. coluzzii

\begin{tabular}{llll}
\hline Variable & Estimate & $95 \% \mathrm{Cl}$ & $P$-value \\
\hline Intercept & 1.16 & $0.59-2.26$ & 0.667 \\
$\mathrm{LC}_{20}$ & 0.72 & $0.41-1.26$ & 0.55 \\
$\mathrm{LC}_{50}$ & 0.58 & $0.27-1.24$ & 0.32 \\
$\mathrm{LC}_{70}$ & 0.52 & $0.23-1.13$ & 0.25 \\
Mean wing length & 0.75 & $0.06-5.45$ & 0.72 \\
\hline
\end{tabular}

attributed their findings to physiological damage caused to the nervous system and associated aberrations due to abnormal hormone release and dehydration as a result of exposure to cypermethrin. Malaria parasites require 8-35 days to develop in their anopheline hosts [33], and therefore reduced adult longevity is widely recognized to reduce the vectorial capacity of a vector population [34]. Under highly controlled laboratory conditions, $10 \%$ and $37 \%$ female mortalities were observed by day 15 in the control and $\mathrm{LC}_{70}$ groups, respectively, suggesting that the 
sublethal doses can potentially contribute to reductions in malaria parasite transmission by reducing the longevity of adults.

Wing length in adult An. coluzzii mosquitoes increased with larval exposure to increasing sublethal $B t i$ concentrations. Similar findings were observed in adult female Ae. aegypti mosquitoes exposed to sublethal concentrations of a naturally derived insecticide, spinosad [35]. The larger mosquitoes emerging from larval development at higher sublethal Bti concentrations may have at least two explanations. First, larger mosquito larvae may be more capable of coping with any stress induced by Bti exposure, and therefore survived exposure to concentrations that smaller larvae could not. Secondly, Bti treatment reduced larval densities and, thus, competition over food and other resources following Bti exposure. Reduced resource competition due to lower larval densities has previously been associated with larger mosquito size [36, 37]. Wing length is used as a standard indicator of body size in mosquitoes [38, 39] as the two measures are positively correlated. Larger females typically produce more eggs because they can take larger blood meals, which means they contribute more offspring to the population [40, 41]. Larger size has also been related with better ability to disperse in Culex pipiens [42]. The potential increase in oviposition rates and dispersal ability for larger mosquitoes may increase their contribution to malaria transmission. Additionally, larger mosquitoes may exhibit reduced susceptibility to the synthetic insecticides used in current vector control tools [43, 44], although it is unclear how this effect might interact with the reduced survival of An. coluzzii exposed to sublethal concentrations of Bti observed in our study. It is also known that smaller female mosquitoes require multiple blood meals before they can reproduce, thus increasing their contact with hosts and effectively becoming more efficient vectors [37]. Therefore, the impact of larger adult An. coluzzii mosquitoes on malaria parasite transmission due to sublethal Bti concentrations remains unclear.

We observed no associations between the mean number of eggs laid and Bti treatment. Similar findings have been observed in another malaria vector, An. superpictus, also exposed to sublethal concentrations of Bti as larvae under laboratory conditions [28]. Also, the results agree with observations made on $A e$. aegypti under similar conditions [26]. Our study might have been limited by clustering of the 25 gravid females in an oviposition cage containing only one oviposition cup. Clustering of females in a cage might have led to egg retention in some of the females as a way of avoiding competition for oviposition space. Evidence of egg retention has been reported in gravid female mosquitoes in absence of suitable oviposition sites [45]. The mean wing length of gravid females also was not associated with the number of eggs laid per cage. The averaging of wing lengths of gravid females might have masked small but meaningful variations in wing sizes due to treatments. Despite not significantly explaining differences in the egg counts between control and treatment groups, we observed a declining trend in median number of eggs laid with increasing Bti concentrations. This effect deserves further study, as a reduction in the number of eggs with larval exposure to Bti would directly reduce vector population size.

\section{Conclusions}

Exposure of An. coluzzii larvae to sublethal Bti doses reduced longevity of adult $A n$. coluzzii and was associated with larger adult size. Whether the increased size is mechanistically linked to Bti toxins or decreased larval density is unclear. There was not a clear effect of larval exposure to Bti on oviposition. It remains important to apply the recommended dosage when applying $B t i$ for malaria vector control, as concentrations high enough to kill larvae before they emerge as adults provide the most effective control against malaria parasite transmission. Still, the effect of sublethal Bti exposure could lead to a reduction in vectorial capacity for malaria vector populations by increasing mortality of adults that survived exposure to Bti in their larval stage.

\section{Supplementary information}

Supplementary information accompanies this paper at https://doi. org/10.1186/s13071-020-04132-z.

Additional file 1. Additional tables.

\section{Abbreviations}

Bti: Bacillus thuringiensis israelensis; WDG: water-dispersible granule; LSM: larval source management; LC: lethal concentration.

\section{Acknowledgements}

We are grateful to Pieter Rouweler, Joeri Groot, Seppe Salari, Frans K. M. van Aggelen and André J. Gidding for mosquito rearing.

\section{Authors' contributions}

SG, CJMK, WT, RSM and JS designed the study. SG performed experiments. SG and JC analysed data. SG drafted the manuscript. WT, JS, CJMK, TM, RSM and $\mathrm{HB}$ revised the manuscript. All authors read and approved the final manuscript.

\section{Funding}

This work was supported by Dioraphte Foundation, The Netherlands. The content is solely the responsibility of the authors and does not necessarily represent the official views of the funders. RSM received additional support from an NIH-funded postdoctoral fellowship (T32AI007524). 


\section{Availability of data and materials}

Data supporting the conclusions of this article are included within the article. The datasets used and/or analysed during the present study are available from the corresponding author upon reasonable request.

\section{Ethics approval and consent to participate}

Human blood used to rear the main mosquito colony was obtained from the blood bank (Sanquin, The Netherlands) where donors filled out an informed consent. The female mosquitoes emerging from larvae that survived exposure to sublethal Bti doses were fed on human blood via arm feeding. The Medical Research Ethics Committee of Wageningen University concluded that the experimental procedure did not require ethical approval according to the Dutch 'Medical Research Involving Human Subjects Act'.

\section{Consent for publication}

Not applicable.

\section{Competing interests}

The authors declare that they have no competing interests.

\section{Author details}

${ }^{1}$ Laboratory of Entomology, Wageningen University \& Research, Wageningen, The Netherlands. ${ }^{2}$ Training and Research Unit of Excellence, School of Public Health, College of Medicine, Blantyre, Malawi. ${ }^{3}$ Malawi-Liverpool-Wellcome Trust Clinical Research Programme, Blantyre, Malawi. ${ }^{4}$ Malaria Alert Centre, College of Medicine, Blantyre, Malawi. ${ }^{5}$ Center for Vaccine Development and Global Health, University of Maryland School of Medicine, Baltimore, USA.

Received: 3 March 2020 Accepted: 11 May 2020

Published online: 16 May 2020

\section{References}

1. WHO. World Malaria Report 2018. Geneva: World Health Organization; 2018. http://www.who.int/malaria. Accessed 19 Dec 2019.

2. Yé Y, Eisele TP, Eckert E, Korenromp E, Shah JA, Hershey CL, et al. Framework for evaluating the health impact of the scale-up of malaria control interventions on all-cause child mortality in Sub-Saharan Africa. Am J Trop Med Hyg. 2017;97:9-19.

3. Guyant P, Corbel V, Guérin PJ, Lautissier A, Nosten F, Boyer S, et al. Past and new challenges for malaria control and elimination: the role of operational research for innovation in designing interventions. Malar J. 2015;14:279.

4. Ranson H, N'Guessan R, Lines J, Moiroux N, Nkuni Z, Corbel V. Pyrethroid resistance in African anopheline mosquitoes: What are the implications for malaria control? Trends Parasitol. 2011;27:91-8.

5. Karaağaç SU. Insecticide resistance. In: Perveen F, editor. Insecticides Advances in Integrated Pest Management. Rijeka, Croatia: InTech; 2012. p. 469-78.

6. Hemingway J. The role of vector control in stopping the transmission of malaria: threats and opportunities. Philos Trans R Soc B Biol Sci. 2014:369:20130431.

7. Killeen GF, Govella NJ, Lwetoijera DW, Okumu FO. Most outdoor malaria transmission by behaviourally-resistant Anopheles arabiensis is mediated by mosquitoes that have previously been inside houses. Malar J. 2016:15:225.

8. Killeen GF. Characterizing, controlling and eliminating residual malaria transmission. Malar J. 2014;13:330.

9. Durnez L, Coosemans M. Residual transmission of malaria: an old issue for new approaches. In: Manguin S, editor. Anopheles mosquitoes. New insights into malaria vectors. Rijeka, Croatia: InTech; 2013.

10. Moiroux N, Gomez MB, Pennetier C, Elanga E, Djenontin A, Chandre F, et al. Changes in Anopheles funestus biting behavior following universal coverage of long-lasting insecticidal nets in benin. J Infect Dis. 2012;206:1622-9.

11. Mwangangi JM, Kahindi SC, Kibe LW, Nzovu JG, Luethy P, Githure Jl, et al. Wide-scale application of Bti/Bs biolarvicide in different aquatic habitat types in urban and peri-urban Malindi. Kenya. Parasitol Res. 2011;108:1355-63.

12. Aïssaoui L, Boudjelida H. Larvicidal activity and influence of Bacillus thuringiensis (Vectobac G), on longevity and fecundity of mosquito species. Pelagia Res Libr Eur J Exp Biol. 2014;4:104-9.

13. Kandyata A, Mbata KJ, Shinondo CJ, Katongo C, Kamuliwo RM, Nyirenda F et al. Impacts of Bacillus thuringiensis var. israelensis and Bacillus sphaericus insect larvicides on mosquito larval densities in Lusaka, Zambia. Med J Zambia. 2012:39:33-8.

14. Crickmore N, Zeigler DR, Feitelson J, Schnepf E, Rie JVAN, Lereclus D, et al. Revision of the nomenclature for the Bacillus thuringiensis pesticidal crystal proteins. Microbiol Mol Biol Rev. 1998;62:807-13.

15. Aronson Al, Shai Y. Why Bacillus thuringiensis insecticidal toxins are so effective: unique features of their mode of action. FEMS Microbiol Lett. 2001;195:1-8.

16. Bravo A, Gill SS, Soberón M. Mode of action of Bacillus thuringiensis Cry and Cyt toxins and their potential for insect control. Toxicon. 2007:49:423-35.

17. De Maagd RA, Bravo A, Crickmore N. How Bacillus thuringiensis has evolved specific toxins to colonize the insect world. Trends Genet. 2001;17:193-9.

18. Tetreau G, Alessi M, Veyrenc S, Périgon S, David JP, Reynaud S, Després L. Fate of Bacillus thuringiensis subsp. israelensis in the field: evidence for spore recycling and differential persistence of toxins in leaf litter. Appl Environ Microbiol. 2012;78:8362-7.

19. Fayolle S, Bertrand C, Logez M, Franquet É. Does mosquito control by Bti spraying affect the phytoplankton community? A 5-year study in Camargue temporary wetlands (France). Ann Limnol. 2015;51:189-98.

20. Sneha A, Preet S. Impact of sublethal conventional and biorational larvicidal stress on fitness status in nutritionally challenged Aedes aegypti larvae. Int J Mosq Res. 2016:3:39-46.

21. Muturi EJ, Kim CH, Alto BW, Berenbaum MR, Schuler MA. Larval environmental stress alters Aedes aegypti competence for Sindbis virus. Trop Med Int Heal. 2011;16:955-64.

22. Barreaux AMG, Barreaux P, Thievent K, Koella JC. Larval environment influences vector competence of the malaria mosquito Anopheles gambiae. Malaria World J. 2016;7:8.

23. Shapiro LLM, Murdock CC, Jacobs GR, Thomas RJ, Thomas MB. Larval food quantity affects the capacity of adult mosquitoes to transmit human malaria. Proc R Soc B Biol Sci. 2016:283:20160298.

24. Vantaux A, Ouattarra I, Lefèvre T, Dabiré KR. Effects of larvicidal and larval nutritional stresses on Anopheles gambiae development, survival and competence for Plasmodium falciparum. Parasit Vectors. 2016;9:226.

25. Alto BW, Lord CC. Transstadial effects of Bti on traits of Aedes aegypti and infection with dengue virus. PLoS NegI Trop Dis. 2016;10:e0004370.

26. Flores AE, Garcia GP, Badii MH, Tovar LRM, Salas IF. Effects of sublethal concentrations of $\mathrm{VectoBac}^{\circledR}$ on biological parameters of Aedes aegypti. J Am Mosq Control Assoc. 2004;20:412-7.

27. Wang $L Y$, Jaal Z. Sublethal effects of Bacillus thuringiensis $\mathrm{H}-14$ on the survival rate, longevity, fecundity and F1 generation developmental period of Aedes aegypti. Dengue Bull. 2005;29:192-6.

28. Simsek FM, Akiner MM, Caglar SS. Effects of sublethal concentration of Vectobac 12 AS on some biological parameters of the malaria vector Anopheles superpictus. J Anim Vet Adv. 2009;8:1326-31.

29. Spitzen J, Ponzio C, Koenraadt CJM, Pates Jamet HV, Takken W. Absence of close-range excitorepellent effects in malaria mosquitoes exposed to deltamethrin-treated bed nets. Am J Trop Med Hyg. 2014;90:1124-32.

30. Becker N, Rettich F. Protocol for the introduction of new Bacillus thuring iensis israelensis products into the routine mosquito control program in Germany. J Am Mosq Control Assoc. 1994:10:527-33.

31. Cerstiaens A, Verleyen P, Van Rie J, Van Kerkhove E, Schwartz JL, Laprade $\mathrm{R}$, et al. Effect of Bacillus thuringiensis Cry1 toxins in insect hemolymph and their neurotoxicity in brain cells of Lymantria dispar. Appl Environ Microbiol. 2001:67:3923-7.

32. Sunday OO, Kayode A, Mo A. Laboratory review of sublethal effects of cypermethrin on oviposition, life span and egg development in Culex quinquefasciatus Say (Diptera: Culicidae). Int J Mosq Res. 2016;3:20-5.

33. Ndoen E, Wild C, Dale P, Sipe N, Dale M. Mosquito longevity, vector capacity, and malaria incidence in West Timor and Central Java, Indonesia. ISRN Public Health. 2012:2012:1-5. 
34. Smith DL, McKenzie FE. Statics and dynamics of malaria infection in Anopheles mosquitoes. Malar J. 2004;3:13.

35. Antonio GE, Sánchez D, Williams T, Marina CF. Paradoxical effects of sublethal exposure to the naturally derived insecticide spinosad in the dengue vector mosquito, Aedes aegypti. Pest Manag Sci. 2009;65:323-6.

36. Gimnig JE, Ombok M, Otieno S, Kaufman MG, Vulule JM, Walker ED. Density-dependent development of Anopheles gambiae (Diptera: Culicidae) larvae in artificial habitats. J Med Entomol. 2002;39:162-72.

37. Scott TW, Takken W. Feeding strategies of anthropophilic mosquitoes result in increased risk of pathogen transmission. Trends Parasitol. 2012;28:114-21.

38. Siegel JP, Novak RJ, Lampman RL, Steinly BA. Statistical appraisal of the weight-wing length relationship of mosquitoes. J Med Entomol. 1992;29:711-4

39. Jirakanjanakit N, Leemingsawat S, Thongrungkiat S, Apiwathnasorn C, Singhaniyom S, Bellec C, et al. Influence of larval density or food variation on the geometry of the wing of Aedes (Stegomyia) aegypti. Trop Med Int Heal. 2007;12:1354-60.

40. Briegel H. Fecundity, metabolism, and body size in Anopheles (Diptera: Culicidae), vectors of malaria. J Med Entomol. 1990:27:839-50.
41. Takken W, Klowden MJ, Chambers GM. Effect of body size on host seeking and blood meal utilization in Anopheles gambiae sensu stricto (Diptera: Culicidae): the disadvantage of being small. J Med Entomol. 1998;35:639-45.

42. Alcalay Y, Tsurim I, Ovadia O. Female mosquitoes disperse further when they develop under predation risk. Behav Ecol. 2018;29:1402-8.

43. Owusu HF, Chitnis N, Müller P. Insecticide susceptibility of Anopheles mosquitoes changes in response to variations in the larval environment. Sci Rep. 2017;7:3667.

44. Oliver SV, Brooke BD. The effect of larval nutritional deprivation on the life history and DDT resistance phenotype in laboratory strains of the malaria vector Anopheles arabiensis. Malar J. 2013;12:44.

45. Seenivasagan T, Iqbal ST, Guha L. Forced egg retention and oviposition behavior of malaria, dengue and filariasis vectors to a topical repellent diethyl-phenylacetamide. Indian J Exp Biol. 2015;53:440-5.

\section{Publisher's Note}

Springer Nature remains neutral with regard to jurisdictional claims in published maps and institutional affiliations.
Ready to submit your research? Choose BMC and benefit from:

- fast, convenient online submission

- thorough peer review by experienced researchers in your field

- rapid publication on acceptance

- support for research data, including large and complex data types

- gold Open Access which fosters wider collaboration and increased citations

- maximum visibility for your research: over $100 \mathrm{M}$ website views per year

At BMC, research is always in progress.

Learn more biomedcentral.com/submissions 